\title{
Deodorizing Ability of Houttuynia cordata Thunb. (Dokudami) for Masking Garlic Odor
}

\author{
Hiromi Ikeura (Corresponding author) \\ School of Agriculture, Meiji University \\ 1-1-1, Higashimita, Tama-ku, Kawasaki, Kanagawa, 214-8571, Japan \\ Tel: 81-44-934-7167Ｅ-mail: hikeura@meiji.ac.jp
}

Received: December 6, 2011

Accepted: December 19, $2011 \quad$ Online Published: February 2, 2012

doi: $10.5539 /$ jas.v4n4p245

URL: http://dx.doi.org/10.5539/jas.v4n4p245

\begin{abstract}
The deodorizing activity of dokudami (HouttuyniacordataThunb.) for masking the odor of fresh garlic was investigated, and the volatility of the deodorizing compounds was examined. Two grams of garlic was placed in a beaker and heated for $5 \mathrm{~min}$ at $40^{\circ} \mathrm{C}$. Next, aliquots of 0.01 and $0.05 \mathrm{~g}$ of powdered samples of seven plants (dokudami, thyme, rosemary, coriander, dandelion, spiny sow thistle and green tea) were mixed with $1 \mathrm{ml}$ of volatile or non-volatile dokudami extract and added to the garlic sample. The garlic odor intensity was subsequently evaluated by sniffing by 10 trained individuals. The deodorizing activity test was carried out at 0,3 and $6 \mathrm{~h}$ after adding the dokudami extract. The deodorizing effect of dokudami on masking garlic odor was the highest of any plant and became higher with increased dose. In addition, the deodorizing activity of dokudami increased with time and persisted. Moreover, whether the deodorizing compounds of dokudami were volatile or non-volatile was investigated. The deodorizing activity of a volatile solution of dokudami against garlic was extremely higher than that of dokudami dry powder. Our findings revealed that the deodorizing compound of dokudami is volatile.
\end{abstract}

Keywords: Deodorizing activity, HouttuyniacordataThunb., Garlic, Volatile, Porapak Q, Dokudami

\section{Introduction}

Recently, odors from garbage and excrement and body odors generated by pets and people are causing significant problems in Japan (Tominaga, 2009). To deal with such offensive odors, many deodorizers have been developed. However, there are a growing number of diverse sources of offensive odors, and consumers have demanded development of deodorizers that are pleasant smelling and safe with regard to hygiene and the environment.

The emission of a variety of molecules by people is influenced by genetics, diet, stress and disease. Halitosis (bad breath) frequently causes embarrassment, may affect interpersonal social communication (Bosy, 1997) and has become an important market for the pharmacological and cosmetic industries (Scully, 2008). Halitosis results from ingesting certain foods and drinks, such as spices, garlic, onion and durian, and from habits such as smoking tobacco and drinking alcohol. It is usually transient, often caused by sulfur-containing volatile agents and is considered to arise from both intra-oral and extra-oral origins (Suarez et al. 1999). In this study, we aimed to mask the garlic odor that is prevalent after eating garlic and which is generally perceived as unpleasant by many people (Shimizu et al., 2004). Although garlic (Allium sativum L.) is used widely in various food recipes for its unique flavor and nutrition, garlic is also the cause of a malodorous smell after ingestion. Studies have shown that garlic's various sulfur-containing substances are the main cause of its malodor (McDowell and Kassebaum, 1993; Scully et al., 1997). To our knowledge, however, no study has attempted to mask the garlic odor (Tamaki et al., 2008), despite the fact that many studies have investigated the main compounds which contribute to garlic odor (Cai et al., 1995).

Plants exhibit wide-ranging effects that include deodorizing, antibacterial and antioxidant activities. Green tea, which can deodorize bad breath, and ginger, wasabi and bamboo grass, which have antibacterial and bactericidal effects on the bacteria that cause food poisoning have been used successfully since ancient times. Tokita et al. (1984) reported that plant extracts of 40 species across 23 families have the strongest deodorizing effect of 167 species across 65 families of plants, and in particular, they reported that such deodorizing effects are notable in 
the functionally of each plant.

Masuda et al. (2004) studied the deodorizing effect of different types of plant extracts and essential oils with respect to the deodorizing aspect of plant functionally. Catechin in green tea (Kida et al., 2002) and biphenyl compounds in thyme (Nakatani et al., 1989) were identified as deodorant compounds. Essential oil of herbs has many volatile compounds which have a deodorizing effect, and it was reported that essential oil of thyme, rosemary and sage suppressed the trimethylamine odor, which constitutes the main odor of fish-like smells (Kikuchi et al., 1968, 1969). Furthermore, volatile compounds of coriander deodorized an offensive odor stemming from porcine large intestine (Kohara et al., 2006; Ikeura et al., 2010). Additionally, in Japan, many deodorizers utilize volatile aromatic compounds which are advantageous over water-soluble compounds for deodorizing widely diffused offensive odors.

Dokudami (Houttuynia cordata Thunb.) of Saururaceae is known as a medicinal plant in Japan and China (Meng, et al., 2005a, 2005b). Its medicinal effects are antibacterial (Jong and Jean, 1993), anticancer (Kim et al, 2001), antileukemic (Chang et al., 2001) and antioxidant (Chen et al., 2003) and can stimulate anti-platelet aggregation (Nishida et al., 1988). In Japan, dokudami is called jyuyaku according to the Japanese Pharmacopoeia. In some parts of Japan, dokudami is known to have a deodorizing effect. However, the deodorizing effect of dokudami has not been well described and its underlying mechanism and respective compounds remain largely unknown.

In this study, to mask the offensive odor of fresh garlic on bad breath, we investigated the deodorizing effect of rosemary, thyme, dandelion, spiny sow thistle and dokudami and examined the volatility of each deodorizing compound.

\section{Materials and Methods}

\subsection{Materials}

Dokudami (Houttuynia cordata Thunb.) was collected around Hiroshima Prefectural University from May to July 2001, and then cultured in a greenhouse. The stem and leaves were sampled at before flowering stage. Wild grasses such as dandelion (Taraxacum grasses Dahlst.), spiny sowthistle (Sonchus asper L.) and two herbs, thyme (Thymus vulgaris L.) and rosemary (Rosmarinus officinalis L.) were collected at the University farm, and green tea (Camellia sinensis L.) was purchased at a supermarket in Shobara city. The fresh leaves and stems of the plant samples, except for green tea, were dried for overnight at $40{ }^{\circ} \mathrm{C}$ and then homogenized using a blender (Wonder Blender, Osaka chemical Co.). All samples were stored at $-80{ }^{\circ} \mathrm{C}$ until the deodorizing activity test or extraction of volatile compounds.

The fresh garlic sample was purchased at a supermaket in Shobara city, and then crashed by a mixer.

\subsection{Porapak Q Column Extraction Method}

Two gram of dried plant samples were added to $80 \mathrm{ml}$ of $20 \% \mathrm{MeOH}$, and stirred for 24 hours at $25^{\circ} \mathrm{C}$. The mixture was centrifuged at $12,000 \times \mathrm{g}$ for $20 \mathrm{~min}$ at $4^{\circ} \mathrm{C}$, and the filtered supernatant was subjected to the Porapak Q (PQ) column concentration method. We followed the procedure described by Shimoda et al. (1987). The filtrate was passed through a column $(20 \mathrm{~cm}$ length $\times 2 \mathrm{~cm}$ i.d.) packed with $10 \mathrm{~mL}$ of PQ $(50-80$ mesh, Waters Co., Milford, MA), and the filtrated solution was as non-volatile fraction. After the column was washed with $100 \mathrm{~mL}$ of deionized water, adsorbed volatile compounds were eluted with $100 \mathrm{~mL}$ of diethyl ether. The elute was dried over excess anhydrous sodium sulfate for overnight after the addition of an internal standard (10 $\mu \mathrm{L}$ of $1 \%$ cyclohexanol) in order to remove the residual moisture in the extracts. The volume of the extracts was reduced to $100 \mu \mathrm{L}$ by evaporating the solvent under a gentle nitrogen stream.

\subsection{The Deodorizing Activity Test}

The offensive odor sample ( $2.0 \mathrm{~g}$ of the garlic) were placed in a $100 \mathrm{ml}$ conical beaker and heated for 5 minutes at $40{ }^{\circ} \mathrm{C}$, and then 0.01 and $0.05 \mathrm{~g}$ of the samples to dokudami or the wild grasses, herbs and green tea and $1 \mathrm{ml}$ of volatile or non-volatile dokudami extract was added. The odor of the garlic was sniffed by the ten trained members (ten healthy adults, four men and six women, ranging in age from 21 to 47 years), and the deodorizing activity test was carried out after 0,3 and 6 hours. The deodorizing activity against the offensive odor was measured using 5 grades (perfectly deodorized: 0, almost deodorized: 1, considerably deodorized: 2, a little deodorized: 3 , completely not deodorized: 4 ).

\subsection{Statistical Analysis}

The significance of the experimental data was tested using the Turkey-Kramer test at $\mathrm{P}<0.05$. 


\section{Results}

The deodorizing activity of dry powder made from various plants against fresh garlic is shown Figure 1 . The odor intensity against $2.0 \mathrm{~g}$ of garlic (odor intensity 4.0 ) treated with $0.01 \mathrm{~g}$ of dokudami, thyme, rosemary, coriander, dandelion, spiny sow thistle and green tea was 1.5, 1.9, 1.9, 3.0, 3.2, 3.1 and 2.1, respectively. The odor intensity against $2.0 \mathrm{~g}$ of garlic treated with $0.05 \mathrm{~g}$ of dokudami, thyme, rosemary, coriander, dandelion, spiny sow thistle and green tea was $1.0,1.4,1.5,2.2,2.6,2.2$ and 2.1 , respectively. The deodorizing effect of dokudami against garlic was the highest of all plants tested and increased with increasing dose. The deodorizing effect of thyme and rosemary was high and followed that of dokudami. Dandelion and spiny sow thistle did not produce a deodorizing effect against garlic, and the deodorizing activity of green tea was reported to be lower than that of dokudami.

Maintenance of the deodorizing effect of dry powder made from various plants on garlic is shown in Figure 2. The odor intensity of dokudami on garlic was 0.6 at both 3 and $6 \mathrm{~h}$ and persisted. The odor intensity of rosemary and thyme, on the other hand, decreased at 3 and $6 \mathrm{~h}$, but not significantly, at the start of the treatment. The deodorizing effect also persisted, but less so than that of dokudami. Therefore, it is postulated that the deodorizing mechanism of these plants was masked (data not shown). The odor intensity of coriander, dandelion and spiny sow thistle tended to be high at 3 and $6 \mathrm{~h}$ but did not persist. Interestingly, the odor intensity of green tea was 1.5 at $3 \mathrm{~h}$ but 2.2 at $6 \mathrm{~h}$, which was very similar to the intensity at the start of the treatment. Green tea exhibited a slight deodorizing effect, less than that of dokudami. These results showed that the deodorizing effect of dokudami was not only stronger than that of green tea, which is well known to have a strong deodorizing effect, but also more persistent.

To demonstrate whether the deodorizing compounds are volatile or non-volatile, volatile compounds of dokudami were extracted by Porapak Q column concentration extraction (PQ) methods, which are used for volatile extracts. We then evaluated the deodorizing effect of volatile and non-volatile fractions of dokudami on garlic (Fig. 3).

The odor intensity of the volatile and non-volatile fraction of dokudami was 0.3 and 3.5, respectively. The volatile fraction of dokudami was shown to have a significant deodorizing effect, which suggested that the deodorizing component of dokudami was volatile, because the component adsorbed strongly on the PQ resin due to polarity.

\section{Discussion}

The odor of garlic was found to arise from allicin (3-[(S)-2-propenylsulfinyl]-L-alanine) which is converted from alliin (2-propene-1-sulfinothionic acid S-2-propenyl ester) by the enzyme alliinase by destructed tissue (Lee et al., 2003). Alliin is an unstable compound and is broken down into sulfur-containing compounds such as methyl mercaptan (Brodnitz et al., 1971; Yu et al., 1989). It is these sulfur-containing compounds that are directly responsible for the offensive odor of garlic (Block, 1992).

Studies on the deodorizing components and mechanism of deodorizing effects of plant extracts and dry materials have been previously reported (Tokita et al., 1984; Nakatani et al., 1989), and some plant extracts from these studies have been utilized as deodorizing materials (Tanaka and Sugiyama, 2001). In particular, there are many studies on methyl melcaptan causing bad breath. Tokita et al. (1984) reported that perilla plants have an effective deodorizing ability. Additionally, Negishi and Ozawa (1997) examined the deodorizing effect of polyphenol compounds and the reaction pathway of polyphenol oxidase in vegetables and mushrooms and described how these vegetables could be deodorized by the addition of polyphenol and diallyldisulfide. The flavonoid and catechin polyphenols in green tea did not have a deodorizing effect on garlic in this study. Moreover, the deodorizing effect of dandelion on methyl mercaptan was reported to have a deodorizing activity second to dokudami (Urabe et al., 1999), but its deodorizing effect on garlic was not shown at all in the present study. Nakatani et al. (1989) reported that 4'-hydroxy-5,5'-diisopropyI-2,2'-dimethylbiphenyl-3,4-dione in thyme has a deodorizing effect on methyl mercaptan.

Urabe et al. (1994) previously reported that methanol extract from dokudami exhibited a deodorizing effect on methyl mercaptan, but they did not study whether the volatile compounds of dokudami could in fact deodorize. Therefore, we have shown for the first time that the volatile compounds of dokudami do have a deodorizing capability against garlic.

In conclusion, we have demonstrated deodorizing activity of dokudami against fresh garlic and clarified that the deodorant compounds were volatile. The deodorizing effect of dokudami against garlic was the highest of all the studied plants and increased in line with increased dose and time. Moreover, the deodorizing activity of the 
volatile solution of dokudami against garlic was extremely higher than that of dokudami dry powder. Results revealed that the deodorizing compound of dokudami is volatile. In near future, we need to identify the deodorizing compounds and elucidate the deodorizing mechanism.

\section{References}

Block E. (1992). The organosulfur chemistry of the genus Allium-Implications for the organic chemistry of sulfur. Angewandte Chemie International Edition, 31, 1135-1178. http://dx.doi.org/10.1002/anie.199211351

Bosy A. (1997). Oral malodor: philosophical and practical aspects. Journal-Canadian Dental Association, 63, 196-201.

Brodnitz MH, Pascale JV \& Derslice LV. (1971). Flavor component of garlic extract. Journal of Agricultural Food Chemistry, 19, 273-275. http://dx.doi.org/10.1021/jf60174a007

Cai XJ, Block E, Uden PC, Quimby BD \& Sullivan JJ. (1995). Allium Chemistry: Identification of natural abundance organoselenium compounds in human breath after ingestion of garlic using gas chromatography with atomic emission detection. Journal of Agricultural Food Chemistry, 43, 1751-1753. http://dx.doi.org/10.1021/jf00055a001

Chang JS, Chiang LC, Chen CC, Liu LT, Wang KC \& Lin CC. (2001). Antileukemic activity of Bidens pilosa L. var. minor (Blume) Sherff and Houttuynia cordata Thunb. The American journal of Chinese medicine, 29, 303-312. http://dx.doi.org/10.1142/S0192415X01000320

Chen YJ, Huang LW \& Shih TS. (2003). Diagnosis of oxide films by cavitation micro-jet impact.Materials Transactions, 44, 327-335. http://dx.doi.org/10.2320/matertrans.44.327

Ikeura H, Kohara K, Li X-X, Kobayashi F \& Hayata Y. (2010). Identification of (E,E)-2,4-undecadienal, from Coriander (Coriandrum sativum L.) as a Highly Effective Deodorant Compound against the Offensive Odor of the Porcine Large Intestine. Journal of Agricultural Food and Chemistry, 58, 11014-11017. http://dx.doi.org/10.1021/jf102297q

Jong TT \& Jean MY. (1993). Alkaloids from Houttuyniae cordata. Journal of the Chinese Chemical Society, 40, 301-303.

Kida K, Suzuki M, Takagaki A \& Nanjo F. (2002). Deodorizing effects of tea catechins on Amines and Ammonia. Bioscience Biotechnology Biochemistry, 66, 373-377. http://dx.doi.org/10.1271/bbb.66.373

Kikuchi T, Hirai K \& Sudarso AS. (1968). Suppressing effect of spice for fishy odor a model experiment with the mixture of trimethylamine and spice. Eiyo to Shokuryo, 21, 253-256.

Kikuchi T, Canh QP \& Osawa I. (1969). Suppressing effect of spice for fishy odor absorption of trimethylamine in spice solutions. Eiyo to Shokuryo, 22, 228-230.

Kim SK, Ryu SY, No J, Choi SU \& Kim YS. (2001). Cytotoxic alkaloids from Houttuynia cordata. Archives of pharmacal research, 24, 518-521. http://dx.doi.org/10.1007/BF02975156

Kohara K, Kadomoto R, Koduka H, Sakamoto K \& Hayata Y. (2006). Deodorizing effect of coriander on the offensive odor of the poricine large intestine. Food Science and Technology Research, 12, 38-42. http://dx.doi.org/10.3136/fstr.12.38

Lee SN, Kim NS \& Lee DS. (2003). Comparative study of extraction techniques for determination of garlic flavor components by gas chromatography-mass spectrometry. Analytical and bioanalytical chemistry, 377, 749-756. http://dx.doi.org/10.1007/s00216-003-2163-z

Masuda J, Hiroshi M \& Joji F. (2004). Deodorization by used tea leaves. Seikatsu Eisei, 48, 92-96.

McDowell JD \& Kassebaum DK. (1993). Diagnosing and treating halitosis. 4. Journal of the American Dental Association, 124, 55-64.

Meng J, Leung KS, Jiang Z, Dong X \& Zhao Z. (2005a). Establishment of GC-MS fingerprint of fresh Houttuynia cordata. Chemical \& Pharmaceutical Bulletin, 53, 1484-1489. http://dx.doi.org/10.1248/cpb.53.1484

Meng J, Leung KS, Jiang Z, Dong X, Zhao Z \& Xu LJ. (2005b). Establishment of HPLC-DAD-MS fingerprint of fresh Houttuynia cordata. Chemical \& Pharmaceutical Bulletin, 53, 1604-1609. http://dx.doi.org/10.1248/cpb.53.1604

Nakatani N, Kayoko K \& Inagaki T. (1989). Structure of new deodorant biphenyl compounds from thyme (Thymus vulgaris L.) and their activity against methyl mercaptan. Agricultural and biological chemistry, 53, 1375-1381. http://dx.doi.org/10.1271/bbb1961.53.1375 
Negishi O \& Ozawa T. (1997). Effect of polyphenol oxidase on deodorization. Bioscience Biotechnology Biochemistry, 61, 2080-2084. http://dx.doi.org/10.1271/bbb.61.2080

Nishida H, Ishiwatari K, Komatsu K, Nakata O, Kitamura K \& Fujii S. (1988). Platelet aggregation inhibitors from jyu-yaku (Houttuyniae Herb). Chemical \& Pharmaceutical Bulletin, 36, 1902-1904. http://dx.doi.org/10.1248/cpb.36.1902

Shimoda M, Hirano K \& Ozajima Y. (1987). Concentration of volatile components in foods with porous polymer column. Bunseki Kagaku, 36, 792-798. (in Japanese with English summary). $\mathrm{http}: / / \mathrm{dx}$. doi.org/10.2116/bunsekikagaku.36.11_792

Scully C, El-Maaytah M, Porter SR \& Greenman J. (1997). Breath odor; etiopathogenesis, assessment and management. European Journal of Oral Science, 105, 287-293. http://dx.doi.org/10.1111/j.1600-0722.1997.tb00242.x

Scully C \& Greenman J. (2000). Halitosis (breath odor). Periodontology, 48, 66-75. http://dx.doi.org/10.1111/j.1600-0757.2008.00266.x

Shimizu K, Maeda Y, Osawa K \& Shimura S. (2004). Deodorizing effect of Rubus suavissimus extract against allyl methyl sulfide. Nippon Shokuhin Kagaku Kogaku Kaishi, 51, 205-209. http://dx.doi.org/10.3136/nskkk.51.205

Suarez F, Springfield J, Furne J \& Levitt M. (1999). Differentiation of mouth versus gut as site of origin of odoriferous breath gases after garlic ingestion. American journal of physiology, 276, G425-430.

Tamaki K, Sonoki S, Tamaki T \& Ehara K. (2008). Measurement of odour after in vitro or in vivo ingestion of raw or heated garlic, using electronic nose, gas chromatography and sensory analysis. International Journal of Food Science and Technology, 43, 130-139. http://dx.doi.org/10.1111/j.1365-2621.2006.01403.x

Tanaka T \& Sugiyama K. (2001). The technical trends of kitchen and kitchen garbage deodorizers in Japan. Fragrance Journal, 10, 37-45.

Tokita F, Ishikawa M, Shibuya K, Koshimizu M \& Abe R. (1984). Deodorizing activity of some plant extracts against methyl mercaptan. Nippon Nogeikagakukaishi, 58, 585-589. http://dx.doi.org/10.1271/nogeikagaku1924.58.585

Tominaga K. (2009). Olfactoly organs and trends in the environmental administration. Japan TAPPI Journal, 63, 1459-1464. http://dx.doi.org/10.2524/jtappij.63.1459

Tsunoda M, Yamada S \& YasudaH. (1996). Deodorizing Mechanism of Epigallocatechin and Chewing Gum Containing Tea Extracts. In: Van-Stteenberghe, D. and M. Rosenberg, (Eds.). Bad Breath, A multidisciplinary Approach. Leuven University Press, Leuven, p.275-282.

Urabe K, Nadamoto T, Kawamura M \& Yasumoto K. (1994). Effects of Houttuyniae cordata and refinery final molasses on the development of offensive odor in porcine small intestine during storage. Journal of nutritional science and vitaminology, 40, 63-71. http://dx.doi.org/10.3177/jnsv.40.63

Urabe K, Nadamoto T, Kawamura M \& Yasumoto K. (1999). Deodorization activity of wild grasses against methyl mercaptan. Nippon Shokuhin Kagaku Kogaku Kaishi, 46, 484-486. (in Japanese). http://dx.doi.org/10.3136/nskkk.46.484

Urabe K, Higashi R, Inada T, Minamin K, Nadamoto T \& Ono K. (2009). Deodorizing effects of wild grass extracts against methanethiol. Food Preservation Science, 35, 171-177.

Yasuda H \& Ui M. (1992). Deodorant effect of plant extract of the family rosaceae against methyl mercaptan. Nippon Nogeikagakukaishi., 66, 1475-1479. (in Japanese). http://dx.doi.org/10.1271/nogeikagaku1924.66.1475

Yasuda H \& Arakawa T. (1995). Deodorizing mechanism of (-)-epigallocatechingallate against methyl mercaptan. Bioscience Biotechnology Biochemisry, 59, 1232-1236. http://dx.doi.org/10.1271/bbb.59.1232

Yu T-H, Wu CM \& Liou YC. (1989). Volatile Compounds from garlic. Journal of Agricultural and Food Chemistry, 37, 725-730. http://dx.doi.org/10.1021/jf00087a032 


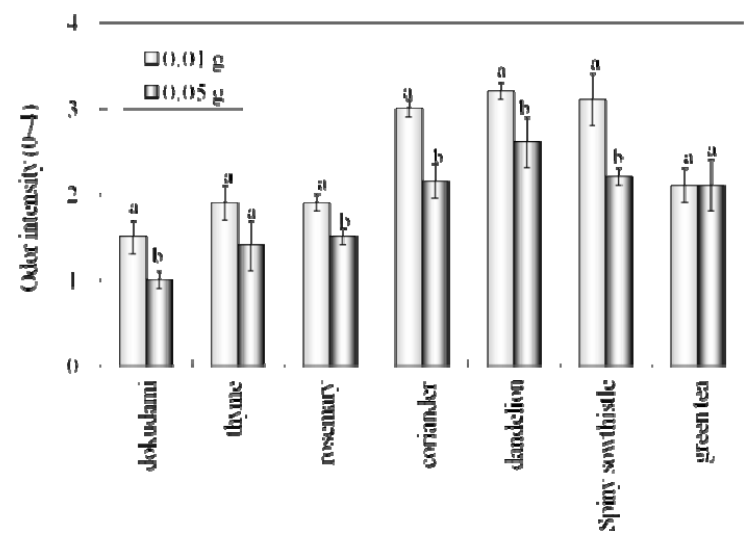

Figure 1. Deodorizing activity of various dry plant materials against garlic

Garlic odor intensity was determined as follows: 0 , perfectly deodorized; 1 , almost deodorized; 2 , considerably deodorized; 3 , slightly deodorized; 4 , completely not deodorized.

The deodorizing activity of dry plant material samples $(0.01 \mathrm{~g}$, white bars; $0.05 \mathrm{~g}$, gray bars $)$ was carried out against $2.0 \mathrm{~g}$ garlic. Values per plant with the same letter do not significantly differ at $\mathrm{p}<0.05$ by the Turkey-Kramer test. Vertical bars represent the standard error of the mean value $(n=3)$.

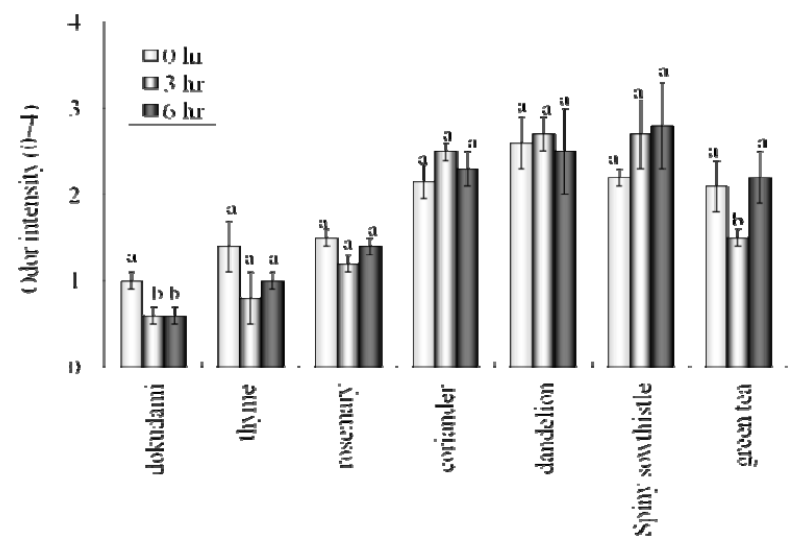

Figure 2. Deodorizing activity of various dry plant materials against garlic after treatment

Garlic odor intensity was determined as follows: 0 , perfectly deodorized; 1 , almost deodorized; 2 , considerably deodorized; 3 , slightly deodorized; 4 , completely not deodorized.

The deodorizing activity of dry plant material samples $(0.05 \mathrm{~g})$ was carried out against $2.0 \mathrm{~g}$ garlic and the deodorizing intensity was measured at initial time (white bars) and after $3 \mathrm{~h}$ (gray bars) and $6 \mathrm{~h}$ (black bars). Values per plant with the same letter do not significantly differ at $\mathrm{p}<0.05$ by the Turkey-Kramer test. Vertical bars represent the standard error of the mean value $(n=3)$.

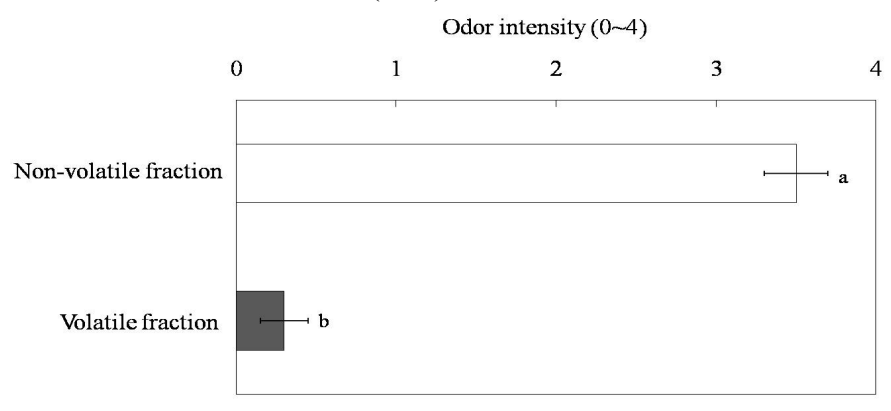

Figure 3. Deodorizing activity of volatile and non-volatile fractions of dokudami against garlic Garlic odor intensity was determined as follows: 0 , perfectly deodorized; 1 , almost deodorized; 2 , considerably deodorized; 3 , slightly deodorized; 4 , completely not deodorized.

The deodorizing activity was carried out against 2.0 g garlic with a 0.5 -g sample pellet with $10 \mathrm{ml}$ supernatant and $1 \mathrm{ml}$ of volatile or non-volatile fraction. Values per plant with the same letter do not significantly differ at $\mathrm{p}<0.05$ by the Turkey-Kramer test. Vertical bars represent the standard error of the mean value $(n=3)$. 